\title{
IMÁGENES FUNDACIONALES DE LA NACIÓN
}

\author{
Hugo Achugar \\ Universidad de la República, Uruguay
}

\begin{abstract}
RES U M O
O artigo retoma as questões a propósito dos temas de nação e do nacionalismo e sua expressão nas artes latino-americanas, ressaltando como, tanto pela sinalização do corpo diaspórico da nação, quanto pela inclusão/alusão do "corpo ausente", que dominou a segunda metade do século XX, a representação e o tratamento dos corpos da pátria presentes em filmes e distintas formas artísticas evidenciam transformações.
\end{abstract}

\section{PALAVRAS - CHAVE}

Nação. Cinema latino-americano. Literatura latina.

El debate sobre nación y nacionalismo ha atravesado las más diversas disciplinas; ha sido estudiado en relación con la literatura, la historia, la memoria, la narración, la etnia, la identidad sexual, el género y la cultura. También ha merecido la atención de quienes se ocupan de las artes visuales o de la comunicación. El presente trabajo recoge, parcialmente, un ensayo en el que vengo trabajando desde hace mucho tiempo; en una versión anterior terminaba afirmando que además de la "ciudad letrada" había existido -mucho antes de que se produjera la apoteosis de la "ciudad televisiva"- una "ciudad visual". ${ }^{1}$

La idea de que el arte visual es expresión de la identidad nacional es un lugar común de la reflexión intelectual; al menos lo fue durante una época. Esta antigua idea se apoyaba en la premisa de que la nación y consecuentemente lo nacional preexistía a la producción artística; es decir, tenía una existencia a-histórica. ${ }^{2}$ De esta concepción propia del Romanticismo surge aquello del "espíritu del pueblo", el "Volkgeist", el "folclore", que durante mucho tiempo alimentó los relatos y las explicaciones acerca del surgimiento de las naciones y de los pueblos.

Hoy en día, la concepción "esencialista" de la nación ha venido perdiendo apoyo y viene siendo sustituida por la idea de la construcción de la nación. Es decir, la concepción que privilegia la idea de que la nación no preexiste al Estado sino que es construida por

\footnotetext{
1 "(...) la transformación en la descripción de los pensamientos/imágenes del sueño de la nación indica que junto a la ciudad letrada, de que hablara Ángel Rama, existía -aun antes de la introducción de la cultura masiva televisiva-, una ciudad visual que mostraba una riqueza y una eficiencia particular." (ACHUGAR. Planetas sin boca, p. 198)

${ }^{2} \mathrm{Al}$ respecto resulta elocuente lo señalado por Cossío y recogido por Inman Fox en La invención de España (1997).
} 
éste o por el sector hegemónico de cada sociedad. La vertiente "construcionista" sin embargo ha sido argumentada fundamentalmente a partir de un análisis de la literatura o desde la letra impresa. Así, Julio Ramos sostiene que

Lejos de lo que la literatura podría ser hoy para nosotros -una actividad relativamente especializada, diferenciada de otras prácticas discursivas y de la lengua común-la nostalgia que se manifiesta en el Prólogo de Martí [al Poema del Niágara de Pérez Bonalde, H.A.] responde a la crisis de un sistema cultural en que la literatura, las letras, más bien, habían ocupado un lugar central en la organización de las nuevas sociedades latinoamericanas. La literatura -modelo, incluso, del ideal de una lengua nacional, racionalmente homogeneizadahabía sido el lugar -ficticio, acaso- donde se proyectaban los modelos de comportamiento, las normas necesarias para la invención de la ciudadanía, los límites y las fronteras simbólicas, el mapa imaginario, en fin, de los estados en vías de consolidación. (8)

En realidad, esta argumentación -a pesar de hablar de "la organización de las nuevas sociedades"- no refiere tanto a la nación como al papel jugado por el Estado en la construcción de la nación centrándose en la importancia de la literatura y de la palabra escrita; algo similar a lo que Benedict Anderson y Doris Sommer han sostenido en sus ensayos e investigaciones. Por el contrario, el presente trabajo intenta argumentar la importancia de lo que he decidido llamar "imágenes fundacionales"; imágenes no menos ficcionales que las "foundational fictions" de Doris Sommer en la construcción de los imaginarios nacionales por parte del Estado y del sector hegemónico o letrado de las sociedades latinoamericanas del siglo XIX y comienzos del XX pero que encuentran su sustento o cuya materialidad es visual y no escrita. En ese sentido, creo que lo propuesto por Sommer, al privilegiar la palabra escrita centrándose en un grupo de novelas latinoamericanas, deja fuera elementos centrales en la construcción de los imaginarios nacionales latinoamericanos que están relacionados con la imagen aun cuando su visualidad dialogue con la palabra escrita.

Por otra parte, mi planteo modifica también las conocidas afirmaciones de Benedict Anderson acerca de la función de la prensa y de la narrativa en la conformación de las "comunidades imaginadas" de la nación durante el siglo XIX e intenta repensar el fenómeno de la construcción de los imaginarios nacionales durante el siglo XX, justo cuando -al parecer- estaríamos en un tiempo "pos nacional". ${ }^{3}$

En un primer momento, el interés fue analizar aquellos "cuadros/imágenes/iconos nacionales" de distintos países, que como es el caso de El Juramento de los 33 Orientales, en Uruguay, El velorio del puertorriqueño Francisco Oller y Cetero (o Cestero) de 1893, la imagen de la Virgen de Guadalupe en México o El 2 de mayo de Goya en España tenían o parecen haber tenido un papel decisivo en la configuración del imaginario nacional.

Una de las primeras sorpresas o dificultades fue descubrir que no en todos los países existían obras plásticas con una función configuradora del imaginario nacional como ocurría en Uruguay y en cierta medida en Puerto Rico. En realidad, en México la imagen de la Virgen de Guadalupe podía o debía ser contrastada con los murales de

\footnotetext{
${ }^{3}$ La eventual etapa "pos nacional" abre la posibilidad de periodizar tanto entre lo "pre" y lo "pos" nacional como entre "la colonia" y lo "pos nacional". El período en que funciona la "máquina" fundacional del imaginario cubre ese largo período que va de lo "pre" a lo "pos nacional".
} 
comienzos del siglo XX y en el caso de España El 2 de mayo de Goya no parecía ejercer una interpelación nacional tan "universal" como ocurría en Uruguay.

Más aún en algunos países como Bolivia o incluso Ecuador no es posible -al menos según las fuentes y los informantes consultados hasta ahora- determinar la existencia de una "imagen fundacional" de la nación. El único cuadro o la única imagen que podría aspirar a desempeñar un papel similar\{WGAJl $\}$ es el pintado por Emmanuel Leutze donde se representa a Washington cruzando el Delaware (1851) e incluso un papel incluso mayor al de "simbolizar" una nación ya que, de acuerdo a lo que el sitio web "americanrevolution.org" sugiere con una candidez a la vez provinciana e imperial:

With the possible exceptions of Da Vincis' Mona Lisa and Last Supper, this is perhaps the most universally recognized image in the entire history of art. (http://www.americanrevolution.org/ delxone.html.)

Las diferencias entre el cuadro uruguayo y el de los EEUU parecerían estar en que en el caso de Blanes la veracidad histórica lo habría llevado incluso a traer arena del lugar histórico a pintar mientras Leutze pintó su cuadro en Alemania incurriendo en numerosos "errores históricos". De hecho, tampoco esto es verdad ya que, como veremos más adelante, Blanes compone racial y numéricamente a los 33 Orientales sin seguir la "verdad histórica" sino un proyecto de representación nacional. En todo caso, y más allá de las peculiaridades de cada cuadro, en ambos lo que importa es su reproducción en espacios públicos y de enseñanza por parte del Estado; lo que permite apreciar cómo una imagen o su reproducción se vuelve fundacional del imaginario nacional con independencia de su "veracidad histórica".

En este sentido, la idea de que lo visual ejerce o cumple un papel fundamental o incluso mayor que el de la letra en la fundación de los imaginarios nacionales me parece que sigue teniendo validez. Sin embargo, la nación nace o es fundada no sólo por imágenes artísticas o plásticas de la alta cultura y se vuelve necesario considerar otro tipo de imaginería o representación visual.

También en esto hay antecedentes. El trabajo de Hans Konig sobre Colombia ha revisado las imágenes presentes en las monedas en el largo camino hacia la consolidación de la nación colombiana. En otra línea y en relación con la Revolución Francesa los trabajos de Lynn Hunt también constituyen antecedentes relevantes. Es precisamente esa otra estrategia visual o si se prefiere esa otra imaginería que debe ser analizada o considerada cuando se estudia la construcción de la nación.

Así y como lo muestra el trabajo de Konig respecto de Colombia tiene particular importancia el universo visual diseñado tanto por los papeles moneda como por las propias monedas metálicas. Pero además creo que deben ser considerados los monumentos, la arquitectura, la fundación o creación de instituciones culturales y muy especialmente la emisión de sellos postales nacionales. Es claro que al constituir un objeto de conocimiento heterogéneo en cuanto incluye o supone la presencia de representaciones visuales en general pero también arquitectónicas o simbólicas, se escapa al escenario de una única disciplina o metodología. Pero, a la vez, se trata de un material relativamente "homogéneo" en tanto el conjunto de este material tiene como eje central los procesos e instrumentos de simbolización realizados desde el Estado o los sectores hegemónicos para construir el imaginario de la nación. 
El presente trabajo se limita a considerar unos pocos ejemplos: primero, se retoma el examen de un cuadro de Juan Manuel Blanes en Uruguay y luego se considera el caso de las monedas y de los papeles monedas en algunos países latinoamericanos. Lamentablemente, no se considera en esta oportunidad la función de los monumentos en la construcción de esos lugares que, parafraseando libremente a Pierre Nora, podrían ser llamados más que "lugares de memoria", "lugares de nación" o "lugares de nacionalismo".

\section{La nación naciente: El Juramento de los 33 Orientales $\{$ WGaJl $\}$}

Pocos cuadros históricos latinoamericanos han tenido la suerte de El Juramento de los 33 Orientales. Fechado en 1877, aunque comenzado en 1875, el cuadro de Juan Manuel Blanes se inserta dentro del programa de celebraciones del cincuentenario del comienzo de lo que por entonces se consideraba el inicio de la Independencia uruguaya; en esta oportunidad no de España sino del Brasil. Aunque el cincuentenario se había cumplido precisamente en 1875, el movimiento para celebrar la fecha comenzó antes, en 1874, con la decisión de erigir un monumento conmemorativo y se prolongó hasta la inauguración de dicho monumento en 1879 y la lectura del poema de Juan Zorrilla de San Martín La Leyenda Patria también de 1879. En ese sentido, tanto El juramento de los 33 Orientales, como el poema La leyenda Patria y el monumento de la Florida configuran, parcialmente, esa primera imagen que intenta actualizar el sueño de la nación (Gourgouris) a fines del siglo XIX.

El cuadro en cuestión y el texto de Zorrilla se habrán de convertir en iconos de la nacionalidad uruguaya sobre todo por la acción ejercida desde el Estado en la educación pública; iconos que serán acompañados no sólo por el respaldo que desde el Estado recibieron sino y -tal al menos es lo que ha quedado registrado en la memoria histórica oficial- por el respaldo que la comunidad nacional o, como consignan los historiadores, por el reconocimiento que el "pueblo" le dio a ambas obras. Lo que también podría ser descrito diciendo que tanto el cuadro como el poema interpelaron -en el sentido de Althusser- el "nosotros" de la comunidad uruguaya u oriental.

Pero iqué escenario construye el cuadro de Blanes?

La tela representa una escenificación del episodio histórico en el que un grupo de uruguayos inicia la guerra contra el ejército brasileño que gobierna el país. Luego del desembarco, el cuadro "documenta" -el término no es ingenuo y alude al estilo y a la voluntad representativa del pintor- el momento en que los Orientales se juramentan con el lema de "Libertad o muerte". Los 33 Orientales representados -la documentación histórica sugiere que el número quizás haya sido mayor y se ha especulado que la elección del número de 33 tenga implicaciones con la masonería local-, incluyen tanto figuras del patriciado criollo como mestizos.

En la versión de Blanes, no están representados los negros y los mulatos. Sin embargo, su presencia en el "desembarco de los 33 Orientales" ha sido documentada ya que habrían habido por lo menos dos individuos de origen africano, posiblemente esclavos, así como también italianos. En este sentido, es posible afirmar que el universo diseñado por Blanes otorga al imaginario nacional un cuerpo masculino, blanco y "oriental" que desplaza la clásica representación femenina prescrita por la retórica republicana 
instaurada con la Revolución Francesa (Lynn Hunt), pero que mantiene los ejes étnicos y nacionales como fundamentales.

El Juramento de los 33 Orientales será donado al Estado uruguayo en 1879, el mismo año en que es leído el poema de Zorrilla, por el pintor luego de haber sido exhibido al público durante enero de 1878, en el estudio montevideano de Blanes durante un período prolongado en el que según consta fue visitado por más de 6200 personas (Wschebor, 104). El impresionante desfile, "clamoroso suceso" lo llama Agustín Benzano, reiteraba en parte lo ocurrido en Buenos Aires con otra de sus obras, Un episodio de la fiebre amarilla en Buenos Aires (1871). ${ }^{4}$ Con El Juramento de los 33 Orientales Blanes ve desfilar no sólo familiares de los dichos 33 Orientales que dejaban ramos de flores al pie del cuadro sino una multitud que reconocía y se reconocía en dicha imagen como parte de una "nación naciente". Al decir, de Wschebor:

...el cuadro quedó en exposición más de un mes. En ese sentido la pintura cumplió con su cometido: satisfizo la "necesidad de nación" de los distintos sectores sociales y políticos creando nuevos dioses "sin aura", cuya primera manifestación fue tan efectiva para el imaginario liberal que permaneció diluida en billetes de banco (...) y [...en] el soporte material, para la educación del ciudadano ilustrado... (104)

Wschebor indica al pasar la continuación de la imagen del cuadro de Blanes en los billetes de banco lo que, como veremos después, apunta a la idea de que no sólo a través de las "bellas artes" sino del concreto y poco glamoroso papel moneda se intentó satisfacer la supuesta "necesidad de nación". Esta nación naciente o esta necesidad de nación, es la que había de celebrar el poema de Zorrilla; no hay constancia de que Zorrilla se inspirara en el cuadro de Blanes aunque no hay duda de que lo conoció como también es probable que ambos artistas mantuvieran un diálogo constante. Pero con independencia del mencionado más que probable diálogo, es posible sostener la idea de que estas obras forman parte de un similar movimiento de actualización del sueño de la nación vigente en el imaginario social de la comunidad nacional uruguaya del momento.

En todo caso, en La leyenda Patria de Zorrilla al igual que en El Juramento de los 33 Orientales lo postulado es que se trata del discurso de la Patria. La concentración en la figura de los 33 Orientales no sólo realiza una operación ideológica donde el héroe singular aparece, como en el misterio de la Santísima Trinidad, siendo uno y siendo Treinta y Tres al mismo tiempo, sino que además logra una homogeneización en la que los elementos étnicos son "licuados" en la generalidad del gentilicio "oriental" diferenciado oportunamente del brasileño y del argentino. La ausencia de la figura femenina en la representación de Blanes podría, eventualmente, ser explicada por tratarse de un hecho militar y por la falta de documentación histórica que diera cuenta de la eventual presencia femenina en el "Desembarco de los 33 Orientales". Sin embargo, en otros cuadros histórico bélicos realizados por Blanes la mujer aparece y es motivo de particular preocupación del pintor; especialmente cuando comienza a pintar La Batalla de Sarandí (1881) y siente la necesidad de dar cuenta de mujeres soldados o cuando

\footnotetext{
${ }^{4}$ En esa ocasión, según un cronista de la época, "el pueblo entero, hombres, mujeres y niños, marchó en procesión a admirar la peregrina obra. Durante algunos días la población desbordada rodeó el cuadro como una marca hirviente y rumorosa." (BENZANO, p. 5 y 6).
} 
realiza los cuadros militares en el Palacio de Urquiza o en La batalla de San Cala (1876) donde la dramática imagen de una mujer a caballo casi domina la composición y finalmente en su cuasi póstumo El resurgimiento de la Patria donde la una imagen de la república semi desnuda y envuelta en la bandera nacional aparece junto con la imagen de un indígena a sus pies. Por lo mismo, la ausencia de la figura femenina refuerza la imagen masculina de la nación propuesta por el cuadro de Blanes.

Tanto el texto de Zorrilla como la tela de Blanes fueron, en el momento de su aparición pública, reconocidos por una numerosa parte de la ciudadanía y por supuestos portavoces de los sectores populares como representativos del imaginario nacional vigente. ${ }^{5}$ Sin embargo, eso no significa que los límites de dicho imaginario no presenten o no presupongan tensiones o terrores con relación al Otro. Un Otro que podía ser encarnado indistinta o simultáneamente por el extranjero, la mujer o individuos de otro color de piel. En este sentido, tanto Blanes como Zorrilla confirman la hegemonía del imaginario militarista, masculino y blanco que "oculta" o deja en segundo plano toda representación del cuerpo de la patria que no esté al servicio de dicho imaginario. Precisamente, el paradigma patriarcal y la metáfora de la familia compartidos por Blanes, Hernández y Zorrilla diseñan, entre muchos otros aspectos, un lugar "disciplinado" para la mujer (Barrán), un lugar degradado (Hernández) o un no-lugar (Zorrilla y Blanes) para el negro o el indio así como un lugar de execración para el extranjero. ${ }^{6}$

El Juramento de los 33 Orientales fue reproducido, prácticamente a lo largo de casi todo el siglo XX, en los manuales de enseñanza, en sellos postales y en papeles moneda emitidos por el Estado uruguayo. En ese sentido, la reiteración de la imagen de los 33 Orientales que Blanes creara -tan importante e influyente como la que ofreciera de Artigas- nos permite hablar de la existencia de imagen o imágenes fundacionales de la nación en Uruguay. Pasemos ahora a otras formas y otras imágenes visuales.

\section{Dinero y naCión, o de las dificultades por acuñar la naCión.}

El mayor problema con el análisis de una pintura emblemática en términos de analizar la construcción del imaginario nacional, radica en que de algún modo permanecemos encerrados en el ámbito de las "bellas artes" hegemónico dentro de la "ciudad letrada" de que hablara Ángel Rama. Es decir, permanecemos dentro del ámbito prestigioso y privilegiado de la "alta cultura".

La hipótesis que guía esta parte de la investigación es que el poder del Estado o de los sectores hegemónicos en la configuración del imaginario nacional no se limita al ámbito de la alta cultura; a no ser que se sostenga o se considere que los sellos postales, las monedas y los billetes o el papel moneda son -aun cuando menores-formas de alta cultura. Por otro lado, sería posible argumentar que los sellos y las monedas metálicas o el papel moneda pertenecen a otra sub división del arte que sería la del "arte estatal" por oposición al arte privado o arte de la sociedad civil.

\footnotetext{
${ }^{5}$ Como es el caso de la carta poema "enviada" por "Martín Fierro" a Blanes.

${ }^{6}$ Recuérdese la ridiculización en Martín Fierro del italiano a quien se le llama "papolitano".
} 
¿Cuáles fueron las decisiones o las acciones que los Estados-nación latinoamericanos tomaron o realizaron a mediados del siglo XIX y que influyeron en la conformación de los imaginarios nacionales emergentes? ¿A qué recurrieron? Se tenían ya los llamados símbolos nacionales: bandera, escudo, himno, pero era necesario lograr algo más cotidiano. Se organizaron fiestas, festejos, conmemoraciones pero hubo otras actividades que si bien no estuvieron marcadas por necesidades de construir una simbología nacional ya que las razones fueron económico-financieras o comunicativas, también contribuyeron a la construcción de la nación mediante la imagen visual. Algo que permitió desde lo inmediato del trajín de la vida cotidiana, contribuir a reafirmar estos símbolos nacionales que el Estado estaba empeñado en construir o consolidar. ${ }^{7}$

Precisamente, es en lo cotidiano, en el escenario y la utilería de la vida ciudadana que el Estado va a intervenir acuñando monedas, emitiendo papel moneda, imprimiendo sellos postales y donde va a encontrar el lugar apropiado para continuar su labor de consolidación del imaginario nacional. Incluso más, es en el dinámico y cambiante aspecto de la circulación monetaria donde pueden apreciarse los distintos sueños de la nación o mejor aun los avatares por los que atravesó o atravesaron los distintos proyectos de consolidación de los imaginarios nacionales.

El examen del surgimiento de los sellos postales en América Latina e incluso en todas las Américas es revelador de este proceso. ${ }^{8}$ En ese sentido, al examinar el proceso de instauración de los servicios postales y sobre todo de las imágenes presentes en los sellos americanos, se pueden observar distintos momentos de la conformación de los imaginarios nacionales.

Por otro lado, la lenta transición de distintos sistemas postales que, varias décadas después de las luchas de Independencia seguían coexistiendo, permite ver cómo el Estado todavía no había logrado controlar todos los ámbitos del territorio a su cargo. Así, mientras el primer país en tener un sello postal nacional en todas las Américas es Brasil en 1843, hay otros países que no lo lograrán hasta el último tercio del siglo XIX. Lo interesante, sin embargo, es que el análisis de estos sellos postales permite ver cuál es la visualización que los nuevos Estados comienzan a crear. El "sol de mayo" es, en varios países que se independizaron de España, la primera imagen que intenta construir la visualización de la identidad nacional o local. A lo largo del tiempo, comenzaran a aparecer imágenes de los próceres de la Independencia, de la flora autóctona, paisajes o monumentos asociados a la supuesta auto percepción o representación nacional. Así

\footnotetext{
${ }^{7}$ Al igual que en otros siglos, los sectores dominantes eran conscientes del carácter iletrado de la mayoría de la población y también de las dificultades para acceder o ser expuesta a las peculiaridades del arte visual. Esto ha sido considerado en algunos análisis de los frescos y de los bajorrelieves tanto de la antigüedad (recuérdese el conocido pasaje de la Eneida en que Virgilio describe el bajorrelieve que da cuenta de las acciones de Eneas) como de la Edad Media (la representación visual en las catedrales de los hechos bíblicos): pero no sólo ha sido una estrategia desde el Estado en tiempos pretéritos. El muralismo mexicano al servicio de la Revolución a comienzos del siglo XX es un ejemplo más cercano en esta educación estatal mediante la imagen antes del ingreso masivo de los medios de comunicación.

${ }^{8}$ En este sentido Bennington observó hace tiempo que la instauración de los sistemas postales nacionales eran elementos fundamentales no sólo en la narración de la nación sino en su propia constitución.
} 
como símbolos republicanos cuyo origen remoto no está como se podría suponer, necesaria o únicamente, en la Revolución Francesa. ${ }^{9}$

Así mismo, el análisis del discurso de los sellos permite además ver el tardío ingreso en el sistema postal de personajes afro americanos o indígenas aun cuando, como veremos, el uso de imágenes femeninas de indias o amazonas americanas es frecuente en los primeros años de la lucha independentista entre otros países en Brasil, Colombia y Chile; una notoria excepción es la de Haití.

Pero si el sistema postal puede ser un modo de mostrar la búsqueda de consolidación del imaginario nacional a través de imágenes visuales que circularon en la vida cotidiana, algo diferente va a ocurrir con las monedas y con el papel moneda. Es cierto que el proceso de acuñación de monedas y de emisión de papel moneda no fue linear ni homogéneo. En muchos países la debilidad de los estados-nación permitió que su labor se viera interferida por el sector privado. No sólo por bancos privados que emitieron durante mucho tiempo -en algunos países hasta casi finales del siglo XIX- sus propios billetes o papel moneda sino también por parte de productores y hacendados, como ocurrió en Costa Rica, donde la acuñación de monedas o instrumentos de intercambio comercial estuvo en manos de productores cafetaleros quienes llegaron a acuñar monedas con imágenes de los propios hacendados.

En este sentido, cabría revisar las propuestas de algunos polítologos o de algunos economistas que ligan o ligaban el establecimiento de los estados-nación a la existencia real o potencial de configuraciones económicas a las cuales les interesaba la constitución de aparatos estatales que coincidieran con sus intereses económicos (alambrados de campos, poder judicial y policial, etc). El tema importa pues hoy en día se argumenta que la globalización económico-financiera es lo que habilita el hablar de una era pos nacional o de las configuraciones de comunidades regionales como la Confederación Sudamericana de Naciones o la Comunidad Europea. De hecho, el tema de la moneda es central en la constitución o consolidación de dichas comunidades supra nacionales.

Por otra parte, el interés por "marcar lo nacional" desde el inicio mismo de la gesta independentista en la emisión de monedas o papel moneda puede ser apreciado en varios países. Así, en Venezuela, luego de declarada la Independencia, el Supremo Congreso decreta, con fecha 27 de agosto de 1811, una "ley para la creación de un millón de pesos en papel moneda, para la Confederación de Venezuela" siguiendo, según Mercedes Carlota de Pardo (37), una idea de Francisco de Miranda. Los billetes, de curso forzoso, "llevaron el Sello de la Confederación, llamado también 'sello de Miranda', (y) tuvo por emblema un sol entre cuyos rayos aparecen siete estrellas que representan las siete provincias que declararon la Independencia, en el centro el número 19 (por el 19 de abril de 1810) y alrededor (la leyenda) Estados Unidos de Venezuela, 1811" (Pardo 38) La corta vida de este papel moneda -que será abolido cuando los realistas retoman el gobierno- así como las dificultades o las resistencias del público a confiar en el papel moneda no sólo complicaron la labor política sino también la económica.

\footnotetext{
${ }^{9}$ Sino en el movimiento independentista de los Países Bajos durante el siglo XVII como es el caso del llamado "gorro frigio" que en realidad es de origen holandés y del cual se habla como un antecedente en los periódicos independentistas argentinos entre 1810 y 1816.
} 
En Colombia, por otra parte, se produjeron varias acuñaciones de emergencia de los patriotas. Las primeras se hicieron en Cartagena en 1811 y poco después siguieron el ejemplo en Santafé. Las monedas emitidas en Cartagena presentaban, al igual que en el caso venezolano, el escudo republicano de la ciudad y eran de cobre. Las emitidas en Bogotá en 1813, bajo las órdenes de Antonio Nariño, se hicieron en plata (Henao) y llevaban una imagen femenina; esta moneda "de poco peso (...) a la que se llamó de la india, porque en el anverso tenía una india coronada de plumas" (Torres García, 32). Su importancia -aun cuando fue una moneda de escasa circulación pues "la emisión de moneda era atributo del Gobierno Federal"- radica en que revela una estrategia diferente a la del caso de Venezuela o a la de los patriotas de Cartagena. Mario Arango Jaramillo anota, al respecto, que dicha moneda:

(...) que tenía en el reverso una granada entre-abierta, con tallo y tres hojas y en el anverso una india coronada de plumas. [fue conocida] como de la india, pero también se la denominó china, quizá por la costumbre de llamar en las casas de Bogotá chinas a las sirvientas, que eran de origen indígena. (72)

Más relevante para nuestro argumento es lo que Arango Jaramillo agrega a continuación:

Sea cual sea el origen del nombre de dicha moneda, marcó un hito en nuestra historia monetaria al sustituir la efigie de los monarcas españoles por la cabeza de una india anodina. En esta forma, simbólicamente, se trataba de afianzar la nueva soberanía y de afirmar el nuevo poder. A?os más tarde, después de la Independencia se harían nuevas acuñaciones de la china. (72)

Mientras en Venezuela el acto simbólico de romper con España y con las monedas que tenían la efigie de Fernando VII o del escudo español, lleva a utilizar una simbología republicana celestial -el sol y las siete estrellas-, Colombia intenta lo vernáculo con la imagen de la india. Esta duplicidad: por un lado, lo simbólico abstracto-genérico y por el otro, lo concreto- vernáculo se repetirá en otros países.

El caso de la india colombiana -que aparece en 1813 y luego en otros momentosy que será luego sustituida por otros símbolos merece más atención. Según Konig:

Hasta eligieron [los criollos, h.a.] para la representación alegórica de la libertad la figura de la amazona americana coronada y armada, la figura de una india. La india que representaba la libertad aparecía en las monedas, en el escudo del país o sobre banderas: en general con una corona de plumas, un carcaj con flechas sobre la espalda, los pies que descansaban sobre un caimán domado. Una de las representaciones más conocidas de la india como símbolo de la libertad es el cuadro del pintor colombiano Pedro José Figueroa, probablemente de 1819, que muestra a Bolívar con la india americana coronada" (20)

El tema de la representación femenina o incluso la presencia indígena en las naciones recién independizadas de América Latina merece un tratamiento aparte. Sobre todo, si al caso de Colombia sumamos el de Haití. En este país, la primera imagen que aparece en una moneda metálica es la de Henri Christophe en 1807; sin embargo en los papeles monedas lo que va a predominar es la imagen simbólica de "las armas de Haití" y recién hacia 1875 aparecerá la primera imagen femenina. Lo interesante del caso de Haití es que las imágenes que aparecerán son mujeres caucásicas, muchas acompañando los retratos de presidentes, como Geffrard o Domingue, de indudable origen africano. 
El caso de Haití, el de la india de Colombia y el de Venezuela muestran que el repertorio simbólico del imaginario nacional estaba regido por dos grandes líneas que implicaron diferentes estrategias. Así, el uso de la imagen femenina es revelador pues según se tome, por un lado, la representación instaurada por las nuevas repúblicas -estadounidense o francesa- durante la modernidad donde la mujer es caucásica o europea. En muchas ocasiones esta mujer es presentada como una figura icónica y universal, a menudo reproduciendo diosas grecorromanas como ocurre con los "gourdes" emitidos en 1884 en Haití donde aparece "Ceres". En cambio, si se toman los casos de representación donde se elige una imagen marcadamente americana o localizada étnica y geográficamente como son los casos de Brasil y Colombia los proyectos o los intentos de construcción y/o manipulación de los imaginarios adquieren o podrían haber adquirido significados diferentes.

Mención aparte merece el caso de Brasil, ya que hacia 1833 -en lo que ha sido considerado como una alegoría del descubrimiento de Brasil (Collin Bruce, Vol. 1, 135)aparece una pareja de indígenas acompañados por una cruz de madera lo que permitiría pensar que la marca americana aun cuando tutelada por el máximo símbolo del cristianismo, es parte del espíritu independentista. Sin embargo y seguramente por las peculiaridades del proceso brasileño de ruptura con Portugal, la utilización de imágenes indígenas no es producto de la Independencia republicana. De hecho, entre 1810 y 1813 -luego de la llegada de la corte portuguesa a territorio brasileño en 1808-, el recién fundado Banco do Brasil en Rio de Janeiro, por orden del Rey, realiza una emisión donde aparece en el lado superior izquierdo la imagen de un indígena con su arco; ${ }^{10}$ lo que viene a tensionar sino a desconstruir la exclusiva y necesaria relación entre la presencia de lo "americano" y la construcción de lo nacional independentista. También es cierto que la llegada de la corte portuguesa en 1808 ha sido entendida como uno de los antecedentes de proceso independentista brasileño.

En el caso de las monedas y de los papeles monedas, sin embargo, hay otro elemento de importancia que debe ser considerado a la hora de analizar la función que cumplieron en la construcción de los imaginarios nacionales. La mayoría de los nuevos Estados latinoamericanos no comenzarán a centralizar y a homogeneizar la emisión de monedas hasta varias décadas después de terminado el proceso de las respectivas independencias. En Colombia, recién a partir de junio de 1846 con la aprobación de la ley "sobre monedas nacionales" es que el Estado comenzará la emisión centralizada de monedas aun cuando el proceso de estabilidad monetaria y eliminación del doble sistema (oro y plata) todavía tendrá un largo camino a recorrer hasta prácticamente las postrimerías del siglo XIX. En este sentido, la emisión de monedas y de papel moneda no tiene o no presenta un curso similar al de otras estrategias simbólicas como la bandera, el escudo o el himno. $\mathrm{O}$ por lo menos, presenta un curso mucho más dinámico que el de los tradicionales símbolos nacionales pues la permanencia de himnos, banderas, escudos y similares en la mayoría de los países ha sido mucho menos estable de lo que en general se cree (Uriarte).

${ }^{10}$ Collin Bruce entiende que se trata de una imagen de Neptuno sin fundamentar su lectura. Seguramente habría que considerar la posibilidad de que no sea un indígena pero la presencia de Neptuno no parece tener mayor sentido o justificación. 
Pero además de este largo proceso de homogeneización monetaria, está el tema de la soberanía. Mucha de la argumentación en torno a la emisión de monedas o de papel moneda ha girado y sigue girando hoy en día -como lo han demostrado los recientes casos de Ecuador o incluso del proceso de instauración del Euro en Europa- en torno al tema de la soberanía nacional. Referencias a la soberanía se encuentran en algunos de los decretos vinculados con la creación de las Casas de la Moneda o con la emisión de monedas de varios países, pero lo interesante es que hasta muy avanzado el siglo XIX, el Estado colombiano siguió autorizando la circulación de monedas extranjeras fundamentalmente francesas y belgas- lo que complica o dificulta la argumentación acerca del efecto de la moneda y del papel moneda en la consolidación del imaginario nacional a pesar de las indias, chinas, granadinos y cóndores que poblaron las monedas colombianas.

Si bien me he detenido en el caso de Colombia, la circulación de monedas de países extranjeros ha sido una constante en la mayoría de los países latinoamericanos hasta el presente, como ha quedado ilustrado en estos días por el reciente decreto de Fidel Castro acerca de la circulación del dólar en Cuba. Independientemente de las razones económico-financieras que llevan a la autorización o a la prohibición de la circulación de monedas extranjeras, parece claro que dicha circulación cumple también un valor simbólico respecto de la construcción de lo nacional.

Precisamente, en relación con el tema de la soberanía y de la construcción del imaginario nacional resulta particularmente interesante detenerse en el caso de la emisión de papel moneda por parte del "Banco de Buenos Ayres" (una sociedad anónima privada con promoción y auspicio del gobierno provincial) a comienzos del siglo XIX tal como lo describe el sitio web del Banco de la Provincia de Buenos Aires:

Al comenzar 1822 se convocó en Buenos Aires una reunión vecinal para discutir el proyecto de establecer un Banco, sus posibles funciones y su organización.

La reunión se celebró el 15 de enero de 1822, al atardecer en la sede del Consulado de Buenos Aires (actual Calle San Martín 137). El Ministro de Hacienda, doctor Manuel José García había cursado las invitaciones y asumió la presidencia. Se acordó en ella constituir un banco de giro, y organizarlo como sociedad anónima privada, con el nombre de Banco de Buenos Ayres, aunque también se lo conoció popularmente como "Banco de Descuentos".

Este primer banco, era también la primera sociedad anónima argentina, en este caso con promoción estatal y capital privado, que alcanzó a un millón de pesos moneda metálica. Entre los accionistas fundadores había nombres representativos de sectores muy diversos: los Anchorena, Bernardino Rivadavia, Juan Manuel de Rosas, Vicente López y Planes, el sacerdote Domingo Belgrano (hermano de D. Manuel Belgrano, creador de la Bandera Argentina), Félix Castro, el general Juan Florencio Terrada, los Parish Robertson (promotores de la inmigración escocesa), los británicos Brittain, Miller, Stewart, Cartwright; e italianos, franceses, españoles, alemanes (...) hacendados, comerciantes, militares, profesionales, clérigos, (http://www.bapro.com.ar/museo/bco_fund.htm)

La presencia de figuras notorias en el proceso de Independencia así como de extranjeros y la diversidad de sectores -militares, clérigos, comerciantes, etc- presentes entre los accionistas del Banco es en sí misma elocuente. Pero además permite entender algunas de las peculiaridades que presentaron las imágenes incluidas en los papeles moneda emitidos por dicha institución. 
El "Banco de Buenos Ayres" será sustituido en 1826 por el "Banco de las Provincias Unidas del Río de la Plata”, (llamado popularmente Banco Nacional, sociedad mixta) pero continuará -incluso en ocasión de la cuarta emisión de 1827- usando el nombre de "El Banco de Buenos Ayres". Precisamente, en la emisión de 1827, las ilustraciones de los billetes de 1 a 50 pesos incluyen además de la consabidas figuras alegóricas femeninas, retratos de Simón Bolívar lo que en el contexto de la lucha por la independencia no sería extraño salvo que no aparece la imagen del Gral. San Martín. Esto posibilitaría hablar de un sentimiento de afirmación hispanoamericana anti español presente o registrable en otros niveles del proceso independentista. Sin embargo, el tema se complica, sin embargo, cuando se observa que además de la imagen de Bolívar -que sólo aparece en el billete de 1 peso y en el de 20- también encontramos las de Washington y Franklin junto a imágenes de una águila, un jinete -probablemente un gaucho o un soldado- y distintas figuras femeninas.

La presencia de próceres de otros países en estos billetes emitidos en la primera década de la vida independiente argentina sólo parece ser explicable por la influencia intelectual y política de los líderes de la independencia estadounidense y como un modo de afirmar el carácter republicano y americanista de la lucha contra España. De todos modos, aun cuando todavía en las décadas inmediatas al triunfo de los movimientos independentistas los estados-nación tuvieran fronteras e identidades mucho más amplias que las adquiridas a fines del siglo XIX -como ocurrió no solo entre Argentina y Uruguay sino también en los países de Centro América y en los que constituían la gran Colombialo que este caso de la emisión argentina de 1827 parece indicar es que junto al impulso por fundar un imaginario en sintonía con la afirmación de la soberanía nacional, el Estado estaba preocupado además por reafirmar el carácter republicano y americanista de su acción. ${ }^{11}$

De lo observado hasta ahora, se podría sostener que las imágenes visuales presentes en monedas y en los billetes o papeles moneda no permiten afirmar que el Estado haya sido el único actor en el establecimiento de un discurso fundacional del imaginario nacional; tampoco sería posible sostener que dicho discurso fue homogéneo y carente de tensiones. Sin embargo, resulta altamente productivo revisar las imágenes que acompañaron tanto las monedas metálicas como los papeles monedas, pues permite ver cómo el Estado negocia -y la utilización de este verbo no es inocente- el o los imaginarios nacionales más allá de la literatura o de la prensa escrita. Pero quizás no habría que limitarse a las imágenes provenientes de cuadros, monedas, sellos y papeles monedas y habría que considerar la política de los distintos estados nación de América Latina que orientó la construcción de monumentos durante las celebraciones de los centenarios en las primeras décadas del siglo XX, cosa que ahora no vamos a hacer. Dichos monumentos e incluso algunos anteriores de finales del siglo XIX también son elementos de las "imágenes fundacionales" consideradas anteriormente.

\footnotetext{
${ }^{11}$ Según la Gran Logia Argentina, sin embargo, la explicación es otra y alude -incluyendo en la explicación al Presidente Truman- al hecho de que todos estos próceres pertenecían a distintas logias de la Masonería.
} 


\section{Nuevamente, un final provisorio}

El proceso de construcción o de fundación de los imaginarios nacionales tuvo mucha mayor riqueza que lo que puede surgir si nos limitamos al análisis del discurso letrado de la alta cultura. Por lo mismo, tanto los intereses regionales, como la presencia de agentes privados -sobre todo la banca y los productores o hacendados- y los avatares económico-financieros de estos países -incluida la falsificación de dinero- en relación con el dinero o las monedas extranjeras hacen que el discurso de la nación que los Estados formularon o intentaron formular haya sido extremadamente dinámico y matizado. En este mismo sentido, las imágenes visuales que circularon durante gran parte del siglo XIX e incluso hasta la celebración de los centenarios nacionales a comienzos del siglo XX merecen una atención particular; una atención particular que incluso llevaría a problematizar la misma periodización histórica ya que, al parecer y en estado actual de esta investigación, para considerar el proceso de instauración de las imágenes fundacionales de la nación habría que rebasar ampliamente los límites cronológicos del siglo XIX.

Hoy en día, el "cuerpo de la patria" está más relacionado con el de los jugadores profesionales de deportes -en particular, los futbolistas-, universo predominantemente masculino, al menos en América Latina, y con el cuerpo-objeto de las "Misses", de las modelos o de las actrices. Imágenes que escasamente tienen que ver con los héroes de la Independencia o con las alegorías republicanas de la nación-mujer. Dichos nuevos cuerpos desestabilizan la representación oficial heredada del siglo XIX; quizás no en relación con el paradigma patriarcal, pero sí en relación con otros aspectos de dicho imaginario. Pero estas imágenes no son las únicas que complican el imaginario decimonónico o el oficialmente trasmitido durante el siglo XX, hay "otros cuerpos" y "cuerpos Otros" que hoy también desestabilizan la representación del cuerpo de la patria instaurada a fines del XIX.

En varios países de América Latina el "cuerpo ausente" de los desaparecidos y de sus hijos -a través de filmes, fotografías, monumentos, instalaciones plásticas, marchas, relatos y discursos varios- hacia fines del siglo XX invade o acecha el espacio público indicando que la actualización del sueño de la nación presenta un "vacío corporal" que era/es testimonio o indicio de que ha ocurrido una violación de la Nación que no termina de ser elaborada. Así mismo, el "cuerpo ausente" de los migrantes -tanto los que emigran a los EEUU como quizás los más numerosos que migran hacia países vecinos en la propia América Latina o hacia Europa y Australia- también apuntan a otro tipo de "vacío corporal" que no necesariamente logra constituirse como diáspora.

Así, tanto por el señalamiento del cuerpo diaspórico de la nación como por la inclusión/alusión del "cuerpo ausente" que ha dominado la segunda mitad del siglo $\mathrm{XX}$, la representación y el tratamiento del o de los cuerpos de la patria presente en filmes y distintas formas artísticas evidencia algunas de las transformaciones que se han venido cumpliendo. Por eso mismo, lo que antes fuera pesadilla en el sueño de la nación, ahora pasa a integrar la nueva versión del sueño de la nación en muchos países latinoamericanos convirtiendo el cuerpo heroico militar -dictaduras y torturas medianteen una pesadilla del sueño de la nación construido o postulado hacia fines del siglo XX. 


\section{A B STRACT}

This paper revisits the questions of nation and nationalism and their expression in Latin American art, highlighting how, via both the signalizing of the nation's diasporic body and the inclusion of/allusion to the "absent body", which dominated the second half of the $20^{\text {th }}$ century, the representation and the treatment of the bodies of the homeland present in movies and diverse art forms give evidence of transformation.

\section{KEYWORDS}

Latin American cinema. Latino literature.

\section{BIBLIOGRAFÍA}

ACHUGAR, Hugo. Planetas sin boca. Escritos efímeros sobre arte, cultura y literatura. Montevideo: Trilce, 2004.

ANDERSON, Benedict. Imagined Communities. Reflections on the origin and spread of nationalism. London; New York: Verso, 1991.

ANTUNEZ DE OLIVERA. Lista official de los Treinta y Tres patriotas. Montevideo: Estado Mayor Conjunto del Ejército. Departamento de Estudios históricos, 1975.

BANCO DE LA PROVINCIA DE BUENOS AIRES. http://www.bapro.com.ar/museo/ bco_fund.htm

BARRÁN, José Pedro. Historia de la sensibilidad en el Uruguay. Montevideo: Ediciones de la Banda Oriental: FHCE, 1989-1990, 2 v.

BENNINGTON, Geoffrey. Postal Politics and the Institution of the Nation. In: BHABHA, Homi K. (Ed.). Nation and Narration. London: Methuen, 1990. p.121-37.

BENZANO, Agustín N. La obra pictórica de Juan Manuel Blanes; reseña bibliográfica exposiciones - conferencias - homenajes. Montevideo: Impresora uruguaya, 1947.

CARRANZA, Jacinto. Cuántos eran los Treinta y Tres? Montevideo: Talleres Gráficos “\#\#”, 1946.

CHILD, Jorge; JARAMILLO, Mario Arango. Bancarrotas y crisis: Colombia, 1842-1984, América Latina, 1981-1984.[Bogotá]: Biblioteca de El Espectador, c1984.

DE TORRES, María Inés. La nación tiene cara de mujer: mujeres y nación en el imaginario letrado del siglo XIX. Montevideo: Arca, 1995.

FOX, Inman E. La invención de España: nacionalismo liberal e identidad nacional. Madrid: Cátedra, c1997.

GOURGOURIS, Stathis. Dream nation: enlightenment, colonization, and the institution of modern Greece. Stanford, Calif.: Stanford University Press, 1996.

HAITI RÉFERENCE. http://www.haiti-reference.com/economie/finances/monnaie.html 
HERNÁNDEZ, José. Carta que el Gaucho/ Martín Fierro/ dirige a su amigo/ D. Juan Manuel Blanes/ con motivo de su cuadro/ Los Treinta y Tres. (circa 1878) en Poesía gauchesca. Edición, prólogo, notas y glosario de J.L. Borges y A. Bioy Casares. México/ Buenos Aires: FCE. 1955.

HUNT, Lynn. Politics, culture, and class in the French Revolution. Berkeley: University of California Press, 1984.

IRIGOYEN, Emilio. La patria en escena: estética y autoritarismo en Uruguay: textos, monumentos, representaciones. Montevideo, Uruguay : Ediciones Trilce, 2000.

KONIG, Hans-Joachim, ed. en colaboración con Christian Gros, Karl Kohut y FranceMarie Renard-Casevitz. El indio como sujeto y objeto de la historia latinoamericana, pasado y presente. Frankfurt/Main: Vervuet; Madrid: Iberoamericana, 1998.

KONIG, Hans-Joachim. En el camino hacia la Nación. Bogotá: Editorial Banco de la República, 1994.

NORA, Pierre. Les Lieux de mémoire / sous la direction de Pierre Nora. Paris: Gallimard, 1984-1986.

PARDO, Mercedes Carlota de. Monedas venezolanas. Caracas: Banco Central de Venezuela, 1973.

RAMA, Ángel. La ciudad letrada. Hanover: Ediciones del Norte, 1984.

RAMOS, Julio. Desencuentros de la modernidad en América Latina: literatura y política en el siglo XIX. México: Fondo de Cultura Económica, 1989.

SHAFER, Neil; BRUCE, Colin R. Standard catalog of world paper money. Iola, WI: Krause Publications, c1998.

SOMMER, Doris. Foundational fictions: the national romances of Latin America. Berkeley: University of California Press, c1991.

TORRES GARCÍA, Guillermo. Historia de la moneda en Colombia. Bogotá: Imprenta del Banco de la República, 1945.

URIARTE, Javier. Las fechas y la invención del sistema simbólico nacional en América Latina. In: Hugo Achugar, coordinador; Sonia D’Alessandro Alejandro Gortázar, Clara Paladino, Susana Poch y Javier Uriarte. Derechos de memoria: actas, actos, voces, héroes y fechas : nación e independencia en América Latina. Montevideo: Universidad de la República, Facultad de Humanidades y Ciencias de la Educación, Departamento de Publicaciones, 2003. (341-400)

WSCHEBOR, Isabel. Fe y razón en la pintura patriótica. Blanes y la Sociedad de Ciencias y Artes. In: Catálogo Juan Manuel Blanes. La nación naciente 1830-1901. Montevideo: IMM, 2001.

ZORILLA DE SAN MARTÍN, José. La leyenda patria. Montevideo: Ministerio de Educación y Cultura, 1979. 